This is an open access article under the CC BY-NC-ND license (https://creativecommons.org/licenses/by-nc-nd/3.0/) Issue III, November 2020

ISSN 2707-9481

ISBN 978-601-323-207-2

https://doi.org/10.31643/2020.027

Davron Isabaev

Junior Researcher, Institute of General and Inorganic

Chemistry of the Academy of Sciences of the Republic of Uzbekistan, Uzbekistan

Email: davroni84@mail.ru

ORCID ID https://orcid.org/0000-0002-2953-0908
Miyasar Jumanova

Leading Researcher, Institute of General and

Inorganic Chemistry of the Academy of Sciences of the Republic of Uzbekistan

Email: jumanova@mail.ru

ORCID ID https://orcid.org/0000-0002-1291-6126

\title{
Study of the process of obtaining liquid complex fertilizers
}

Abstract. It is shown that possible in principle to obtain new effective forms of liquid complex fertilizers based on the products of nitric acid decomposition of phosphorite flour, ammonium nitrate, potassium chloride of the UE of the Dekhkanabad potash fertilizer plant and ammonium humate from the oxidized coal of the Angren deposit. On the basis of the conducted research, the optimal technological parameters and conditions for obtaining new forms of complex fertilizers were established.

Keywords: ammonium nitrate, phosphate rock, decomposition, potassium chloride, liquid complex fertilizer.

Cite this article as: Isabaev D., Jumanova M. (2020). Issledovaniye protsessa polucheniya zhidkikh kompleksnykh udobreniy [Study of the process of obtaining liquid complex fertilizers]. Challenges of Science. Issue III, p.: 182-184. (In Russian). https://doi.org/10.31643/2020.027

Исабаев Даврон Зикриллаевич

младший научный сотрудник, Институт общей и неорганической химии АН РУз, Узбекистан Email: davroni84@mail.ru

ORCID ID https://orcid.org/0000-0002-2953-0908
Жуманова Миясар Ортиковна ведущий научный сотрудник, Институт общей и неорганической химии АН РУз Узбекистан.

Email: jumanova@mail.ru

ORCID ID https://orcid.org/0000-0002-1291-6126

\section{Исследование процесса получения жидких комплексных удобрений}

\footnotetext{
Абстракт. Показана принципиальная возможность получения новых эффективных жидких комплексных удобрений на основе продуктов азотнокислотного разложения фосфоритовой муки, нитрата аммония, хлорида калия УП Дехканабадского завода калийных удобрений и гумата аммония из окисленного угля Ангренского месторождения. На основе проведенных исследований установлены оптимальные технологические параметры и условия получения новых форм комплексных удобрений.

Ключевые слова: нитрат аммония, фосфоритная мука, разложение, хлорид калия, жидкие комплексные удобрение.
} 


\section{Введение}

За последние годы в мировой практике наблюдается увеличение объемов производства и применения жидких удобрений. Наибольший объем производства жидких удобрений среди развитых стран достигнут в США, Англии, Франции. Объем мирового рынка жидких удобрений оценивается в 2,4 млрд. долл. в 2020 году и, по прогнозам, достигнет 3,0 млрд. долл. к 2025 году, что составит 4,4\% от общего объема сельскохозяйственного производства (Liquid Fertilizers Market, 2020).

Влияние COVID-19 на мировой рынок было минимальным, так как многие компании уже продали продукцию до кризиса, но намечается различные проблемы на следующий год, так как по прогнозам рост спроса на высокоэффективные жидкие комплексные удобрения (ЖКУ) значительно увеличивается. Это объясняется тем, что ЖКУ имеют ряд преимуществ перед твердыми удобрениями. ЖКУ не пылят, не слеживаются, отличаются свободной текучестью, а неблагоприятные климатические условия не оказывают существенного влияния на их качественные показатели. В смеси с ЖКУ возможно эффективное применение микроэлементов и стимуляторов роста растений, гербицидов и инсектицидов, которые вводятся непосредственно в жидкие удобрения. Поэтому изучение процесса получения новых видов ЖКУ с вовлечением местного сырья является актуальной задачей сегодняшнего дня.

\section{Метод}

Для проведения лабораторных экспериментов использовали фосфоритовую муку состава (вес., \%): $\mathrm{P}_{2} \mathrm{O}_{\text {5общ. }}$ 17,20; $\mathrm{CaO} 43,22 ; \mathrm{Al}_{2} \mathrm{O}_{3}$ 1,24; $\mathrm{Fe}_{2} \mathrm{O}_{3} 1,05 ; \mathrm{MgO}$ 1,75; F 2,00; $\mathrm{CO} 2$ 15,00, азотная кислота с концентрацией 57\%, аммиак, калий хлористый порошкообразный (содержание хлорида калия $\mathrm{KCl}$, $95 \%$ ) и гумат аммония, полученного из окисленного угля Ангренского месторождения.

Комплексные удобрения получены на основе продуктов разложения фосфатного сырья азотной кислотой в присутствии расчетного количества воды - абсорбционной жидкости, нитрата аммония, хлорида калия и гумата. Для получения образцов комплексных удобрений фосфориты Центральных Кызылкумов разлагали неконцентрированной азотной кислотой.

Содержание всех форм $\mathrm{P}_{2} \mathrm{O}_{5}$ (общей, усвояемой, водорастворимой) в исходном сырье и полученных продуктах определяли фотокалориметрическим методом в виде желтого фосфорнованадиевомолибденового комплекса на фотокалориметре КФК-3 ( $\lambda=440$ нм) (Метод инструкция, 2010). Содержание азота - методом отгонки аммиака по Кьельдалю и хлораминовым методом (ГОСТ 30181.4-94, 1996). Содержание калия в полученных образцах определяли по методике (Стифатов и Рублинецкая, 2013). Определение содержания всех форм кальция проводили объемным комплексонометрическим методом титрования трилоном Б в присутствии индикаторов флуорексона или хром-темносинего.

\section{Результаты и обсуждение}

Определен химический состав (табл.1), и изучены физико-механические свойства полученных новых жидких комплексных удобрений. Комплексное удобрение $\left(\mathrm{N}: \mathrm{P}_{2} \mathrm{O}_{5}: \mathrm{K}_{2} \mathrm{O}=1: 1: 1\right)$, полученное при $30 \%$-ной норме азотной кислоты содержит 7,21 \% общего азота, из них 35,12\% находится в аммиачной, а остальное $64,88 \%$ в нитратной формах, 7,02\% $\mathrm{P}_{2} \mathrm{O}_{5}$ общ., из них $35,14 \%$ находится в усвояемой форме, 7,06 \% $\mathrm{K}_{2} \mathrm{O}, 17,53 \% \mathrm{CaO}$ общ., $\mathrm{CaO}$ усвояемой $6,05 \%$ и воднорастворимой 4,287 $\%$. Оно в основном состоит из нитрата кальция - $12,17 \%$, нитрата аммония $-14,22 \%$, моно- и дикальцийфосфатов, а также фосмуки в активированной форме - 28,15 \% и хлорида калия - 12,1\%. Сумма питательных веществ. составляет $29,28 \%$.

Таблица 1. Химический состав жидких комплексных удобрений

\begin{tabular}{|c|c|c|c|c|c|c|c|c|}
\hline $\mathrm{N}: \mathrm{P}_{2} \mathrm{O}_{5}: \mathrm{K}_{\mathbf{2}} \mathrm{O}$ & N общ. & $\mathbf{P}_{2} \mathrm{O}_{\text {5об̆щ. }}$ & $\mathbf{P}_{2} \mathbf{O}_{\text {уусв. }}$ & $\mathbf{P}_{2} \mathrm{O}_{\text {5водн. }}$ & $\mathrm{CaO}_{\text {обшщ. }}$ & $\mathrm{CaO}_{\text {усв. }}$ & $\mathrm{CaO}_{\text {водн. }}$ & $\mathbf{K}_{2} \mathbf{O}$ \\
\hline \multicolumn{9}{|c|}{ при норме $\mathrm{HNO}_{3}=30 \%$} \\
\hline $1: 0,5: 0,5$ & 11,32 & 5,10 & 1,82 & 0,20 & 13,64 & 4,84 & 3,40 & 5,60 \\
\hline $1: 1: 1$ & 7,21 & 7,02 & 2,54 & 0,24 & 17,53 & 6,05 & 4,28 & 7,06 \\
\hline $1: 1: 2$ & 6,54 & 6,14 & 2,35 & 0,25 & 15,69 & 5,32 & 3,62 & 12,11 \\
\hline
\end{tabular}


при норме $\mathrm{HNO}_{3}=70 \%$

\begin{tabular}{ccccccccc}
\hline $1: 0,5: 0,5$ & 11,25 & 5,38 & 4,23 & 1,19 & 13,53 & 10,55 & 7,80 & 5,41 \\
\hline $1: 1: 1$ & 6,28 & 6,35 & 4,86 & 1,42 & 15,81 & 12,11 & 8,74 & 6,22 \\
\hline $1: 1: 2$ & 5,83 & 5,64 & 4,82 & 1,26 & 14,19 & 11,22 & 8,20 & 11,54 \\
\hline
\end{tabular}

С увеличением количества нитрата аммония в составе суспензии, т.е. с изменением соотношения $\mathrm{N}: \mathrm{P}_{2} \mathrm{O}_{5}: \mathrm{K}_{2} \mathrm{O}$ от $1: 1: 2$ до $1: 0,5: 0,5$, коэффициент разложения фосфоритовой муки повышается от $35,21 \%$ до $36,57 \%$.

Повышение нормы азотной кислоты до 70 \% для разложения фосмуки с соотношением $\mathrm{N}: \mathrm{P}_{2} \mathrm{O}_{5}: \mathrm{K}_{2} \mathrm{O} \quad 1: 1: 2$ приводит к увеличению содержание усвояемого фосфора и кальция до 4,82\% и $11,22 \%$ соответственно. Коэффициент разложения фосфоритовой муки в этих условиях изменяется до $74,78 \%$

\section{Выводы}

На основе полученных экспериментальных данных установлено, что полученные жидкие комплексные удобрения на основе азотнокислотного разложения фосмуки с нитратом аммония, хлоридом калия и гуматом аммония отвечает требованиям сельского хозяйства и рекомендуется применять при корневой и внекорневой подкормке всех видов сельскохозяйственных культур методом опрыскивания или внесением на почву в период активной вегетации.

Ссылка на данную статью: Исабаев Д. З., Жуманова М. О. (2020) Исследование процесса получения жидких комплексных удобрений. Материалы Международной практической интернет-конференции «Актуальные проблемы науки» [Challenges of Science]. Выпуск III, стр. 182-184.

https://doi.org/10.31643/2020.027

\section{Литературы}

[1] Liquid Fertilizers Market (2020)- Global Forecast to 2025/ https://www.marketsandmarkets.com.

[2] ГОСТ 30181.4-94 (1996) Методы определения суммарной массовой доли азота, содержащегося в сложных удобрениях и селитрах в аммонийной и нитратной формах //Межгосударственный совет по стандартизации, метрологии и сертификации - Минск: -. -7 с.

[3] Методические инструкции выполнения испытаний экстракционной пульпы и экстракционной фосфорной кислоты (2010) // ОАО «Аммофос - Максам», г.Алмалык, -. С. 16-22.

[4] Стифатов, Б.М., Рублинецкая, Ю.В. (2013) Пламенная фотометрия // Метод. указ. к лаб. работе. Самара; - 13 с.

\section{References}

[1] Liquid Fertilizers Market (2020)- Global Forecast to 2025/ https://www.marketsandmarkets.com. (In English).

[2] State standard 30181.4-94 (1996) Metody opredeleniya summarnoy massovoy doli azota, soderzhashchegosya v slozhnykh udobreniyakh i selitrakh $\mathrm{v}$ ammoniynoy i nitratnoy formakh [Methods for determining the total mass fraction of nitrogen contained in complex fertilizers and nitrate in ammonium and nitrate forms] //Mezhgosudarstvennyy sovet po standartizatsii, metrologii i sertifikatsii - Minsk: -. -7 p. (In Russian).

[3] Metodicheskiye instruktsii vypolneniya ispytaniy ekstraktsionnoy pul'py i ekstraktsionnoy fosfornoy kisloty [Methodical instructions for performing tests of extraction pulp and extraction phosphoric acid]. (2010) // OAO «Ammofos - Maksam», g.Almalyk, -. p. 16-22. (In Russian).

[4] Stifatov, B.M., Rublinetskaya, YU.V. (2013) Plamennaya fotometriya [Flame photometry] // Metod. ukaz. k lab. rabote. Samara; - 13p. (In Russian). 